\title{
Hardened Case Properties and Tensile Behaviours of TMT Steel Bars
}

\author{
I.R. Kabir ${ }^{*}$, M.A. Islam \\ Materials and Metallurgical Engineering Department, BUET, Dhaka-1000, Bangladesh \\ *Corresponding author: isratrumana@gmail.com
}

Received April 11, 2013; Revised January 08, 2014; Accepted February 08, 2014

\begin{abstract}
Nowadays, high strength steels are getting very popular all over the world for various applications such as in auto body making, machine parts manufacturing, steel structure buildings, concrete reinforcement, etc. In Bangladesh, use of high strength TMT steels bars has got a momentum in the construction of flyovers, bridges and high rise buildings because of its good combination of the required mechanical properties. In this research work, locally produced high strength TMT reinforcing steel bars $(20 \mathrm{~mm}$ dia.) of two different companies have been investigated. As a part of this research work, at first, details microstructural morphologies of hardened case, transition zone and core of both steels were investigated by optical microscope and they were then photographed. After that, Rockwell hardness was measured on different zones. Tensile tests were also carried by a Universal Testing Machine at room temperature. After tensile tests, details of the fracture modes of the steel bars were studied carefully. The fracture modes were then discussed in terms of chemical compositions and carbon equivalents, resulted microstructures, case and core hardness, depths of hardened case and transition zone of the steel bars.
\end{abstract}

Keywords: TMT steel, hardened case, fracture mode, martensitic structures, shear failure

Cite This Article: I.R. Kabir, and M.A. Islam, "Hardened Case Properties and Tensile Behaviours of TMT Steel Bars.” American Journal of Mechanical Engineering, vol. 2, no. 1 (2014): 8-14. doi: 10.12691/ajme-2-1-2.

\section{Introduction}

Iron and steel industry is one of the major sources for worldwide environmental pollution [1,2]. As a result, steel producers are in tremendous pressure to produce high strength structural steels so that the annual steel consumption as well as environmental pollution could be reduced. For any structure, there is a relation between the extent of earthquake related damages and overall weight of the structure. So, there is also a growing interest within the reinforced concrete industries in using higher strength reinforcing steel bars for light weight high rise buildings. This interest is driven primarily by the relief of congestion of steel bars in columns or beams, particularly in designing of high earthquake resistant buildings $[2,3,4,5,6]$.

Although, the strength of steel can be increased by the addition of various alloying elements, the key problem concerning this steel strengthening route is that it reduces the ductility of the steel as well as the bendability and/or stretch formability [7-13]. In this regard, worldwide as well as local industries have already started to produce high strength thermomechanically treated (TMT) steel bars of various categories. There are various options and parameters that might be controlled precisely to produce TMT steels. For this type of steel bar production, after completion of the hot rolling schedule, the red heated steel bars are passed through a chamber with controlled water flow, Figure 1.

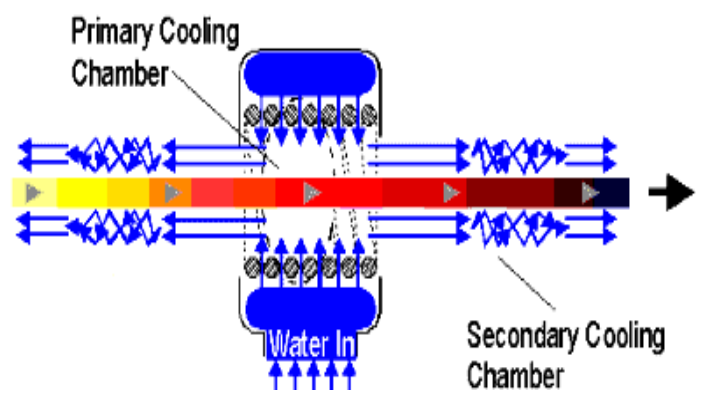

Figure 1. Schematic diagram of water cooling chamber used for TMT steel bar production

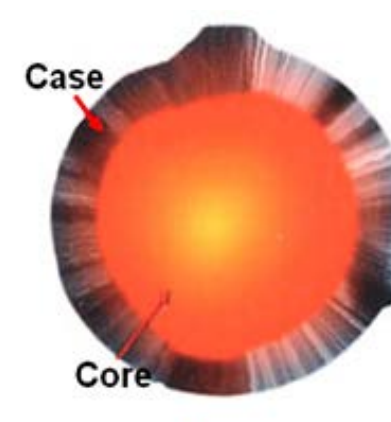

(a)

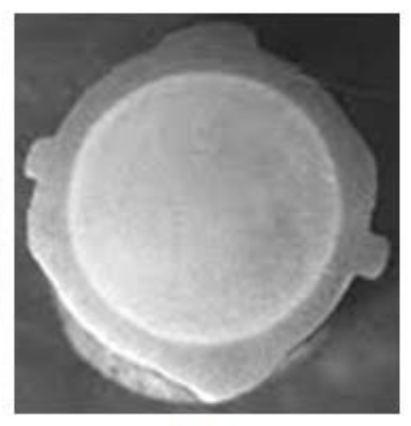

(b)
Figure 2. Cross-section of TMT steel bar just after (a) water quenching and (b) after final cooling

As a result, surface area of the steel bar is got quenched (cooled rapid). However, inside of the bar remains red 
heated, Figure 2a. When this quenched bar is allowed to cool on the cooling bed, the quenched surface gets auto tempered because of heat flow from high temperature core to low temperature surface. So, different microstructural zones are formed, which is very clear from Figure $2 b$. Finally, microstructures of the surface area (called case area) become tempered martensitic (very strong) and the core microstructures become ferrite-pearlite type similar to that of conventional mild steel, Figure 3. In between case and core there might be another area called transition zone. For this steel bar, case areas provide extra strength and core areas provide extra ductility. As a result, this type of steel bar provides overall high strength and ductility, which are very essential for civil engineering, i.e. concrete reinforcing applications.

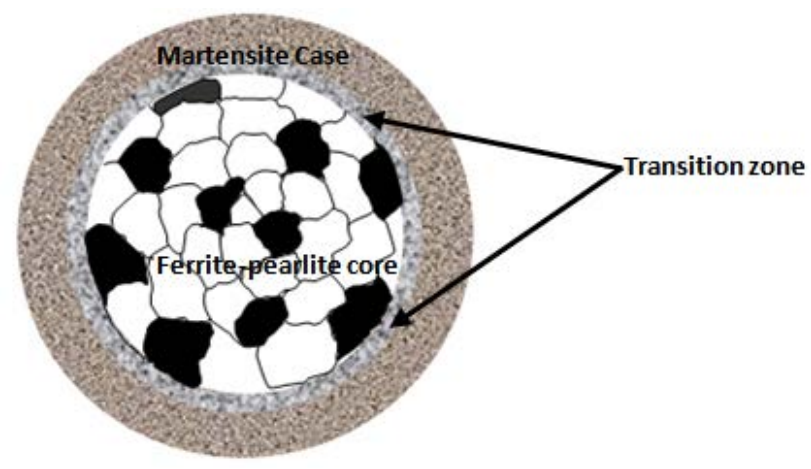

Figure 3. Cross-section of multi-layered microstructures of TMT steel bars

Although, the production process is not of very highly technology oriented, there might be severe degradation in mechanical properties, if the surface cooling rate of steel bar in the water cooling chamber is not synchronized with that of the chemical compositions of the steel bar. For imbalanced cooling rate, the case area will be either very soft or hard. For soft case, the steel will not provide optimum design strength. On the other hand for very hard case the steel will not provide optimum ductility, which might cause brittle type of failure. In this research work, initiative has been taken to investigate the effect of high hardness values of hardened case and core areas and area fraction of transition zone of the steel bars on their tensile strength, ductility, fracture behaviour and possible future consequences if they are used as reinforcing steel bars.

\section{Materials and Experimental Procedure}

\subsection{Materials}

The materials used in this experiment were locally produced TMT high strength steel bars of two different companies. They were collected from the local market.

\subsection{Experimental Procedure}

At first, the chemical compositions of the collected steel bars were known by optical emission spectroscopy (OES). For doing this, samples were cut from the stock materials and they were prepared for the OES. At least three sparks were taken for each group and the averages were considered as the representative chemical compositions of the steel bars. In order to know the microstructures and depth of the hardened zones of the TMT steel bars, metallographic samples were also cut and prepared them for observation under metallurgical microscope following standard procedure. With the help of the micrometer fitted with the microscope, the case depths and thus case areas were calculated. After clearly identifying the core and case areas, series of hardness measurements were carried on individual zones and their averages were considered as the representative hardness of the respective zones.

The microstructures at different zones of the high strength steel bars were also observed under optical microscope and they were photographed. To know the mechanical behaviours of the steel bars, conventional tensile tests were carried out using a Universal tensile testing machine. From these tests, yield strengths, ultimate tensile strength and percentage of elongations were known. Finally, gross fracture modes of the tensile test samples were observed under optical microscope. Here it is to be mentioned that tensile tests were carried for samples of two different surface conditions; namely with and without rib to understand the effect of surface conditions and presence of rib on the tensile fracture mode. Tensile samples used in this investigation are shown in Figure 4.

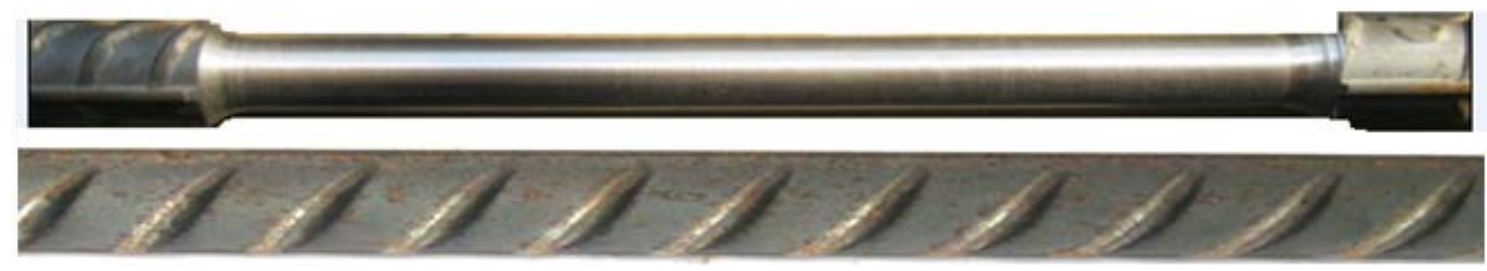

Figure 4. Tensile test sample with and without rib

\section{Results and Discussion}

The chemical compositions of the TMT high strength steel bars are presented in Table 1. From this table, it is clear that the chemical compositions of both steel bars are somewhat different from each other. In order to know the combined effect of the alloying elements of the steel bars, their carbon equivalent (CE) values were also calculated using the well known equation as given below following others $[14,15,16]$. The CE values thus obtained are also presented in Table 1.

$$
\begin{aligned}
C E= & \% C+\left(\frac{\% M n+\% S i}{6}\right) \\
& +\left(\frac{\% C r+\% M o+\% V}{5}\right)+\left(\frac{\% C u+\% N i}{15}\right)
\end{aligned}
$$

From Table 1, it is revealed that the bars have different $\mathrm{CE}$ values. To know the case depth of the hardened zone 
of the TMT steel bars, case depths of around 20 places were measured and their averages were considered as the representative value. The average case depths and hardness of case and core areas are given in Table 2.

Table 1. Chemical compositions of the steel bars used

\begin{tabular}{|c|c|c|c|c|c|c|c|c|c|c|}
\hline Steel ID & Fe & $\mathbf{C}$ & $\mathbf{S i}$ & $\mathbf{M n}$ & $\mathbf{S}$ & $\mathbf{P}$ & $\mathbf{C u}$ & $\mathbf{C r}$ & $\mathbf{N i}$ & $\mathbf{C E}$ \\
\hline 1 & 98.60 & 0.16 & 0.14 & 0.7 & 0.01 & 0.01 & 0.24 & 0.07 & 0.07 & 0.33 \\
\hline 2 & 98.74 & 0.18 & 0.20 & 0.7 & 0.01 & 0.01 & 0.10 & 0.03 & 0.03 & 0.35 \\
\hline
\end{tabular}

Table 2. Depth of hardened zones, hardness values of case and core

\begin{tabular}{|c|c|c|c|}
\hline Steel ID & Case Depth, $\mathrm{mm}$ & Case Hardness, HRC & Core Hardness, HRB \\
\hline 1 & 2.2 & 29.5 & 88 \\
\hline 2 & 2.2 & 32.3 & 91.5 \\
\hline
\end{tabular}

From Table 2, it is clear that the case depths of both steels are very similar. This will also be visually clear shown in Figure 5. However, in steel 2 the case depth is from the macrographs of the cross section of the steel bars somewhat non-uniform.
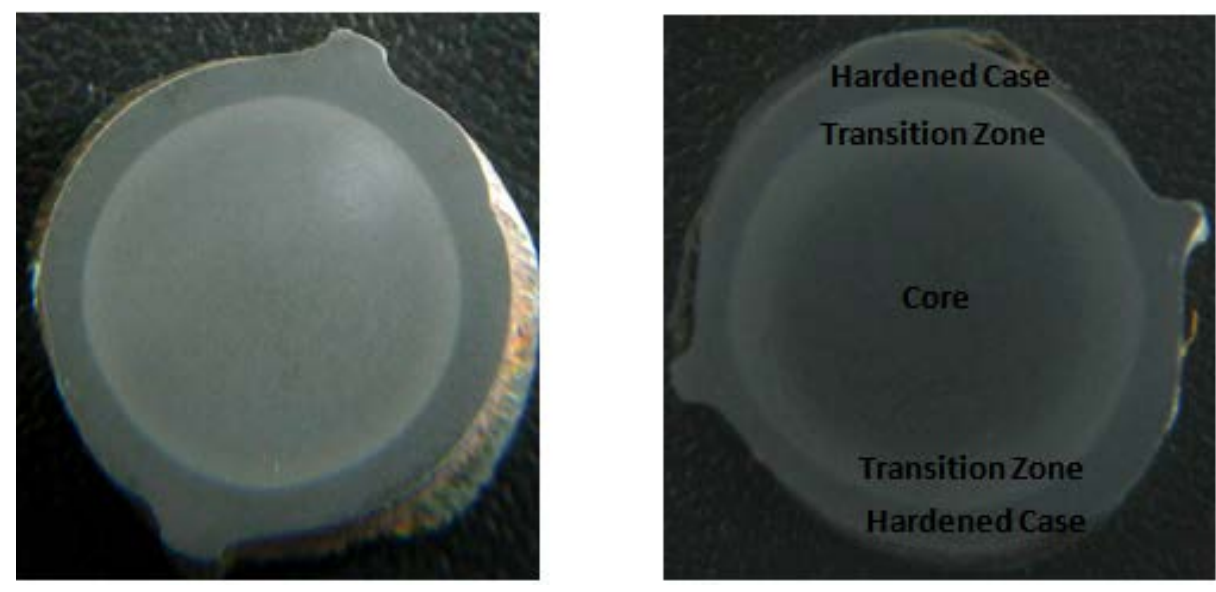

Figure 5. Macrographs showing case depth of steels (a) 1 and (b) 2

Table 2 shows that both the core and case hardness values of steel 2 are much higher than that of steel 1 . One of the reasons behind this is its higher carbon content or
CE value. The microstructures of different zones (case, transition and core areas) of steels 1 and 2 are presented Figure 6 and Figure 7.

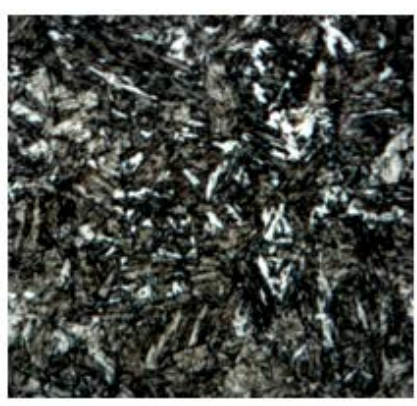

(a)

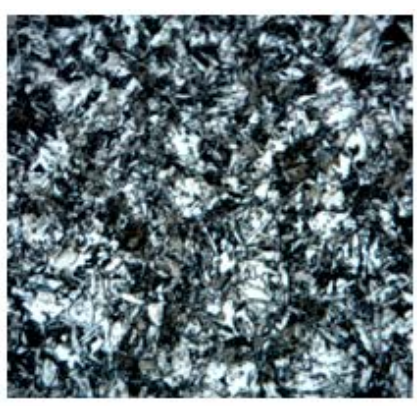

(b)

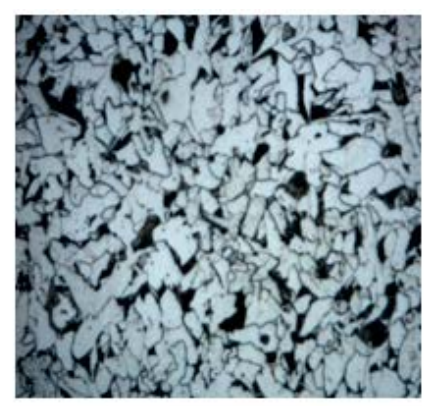

(c)

Figure 6. Optical micrographs showing the microstructures of (a) case, (b) transition and (c) core areas of steel 1

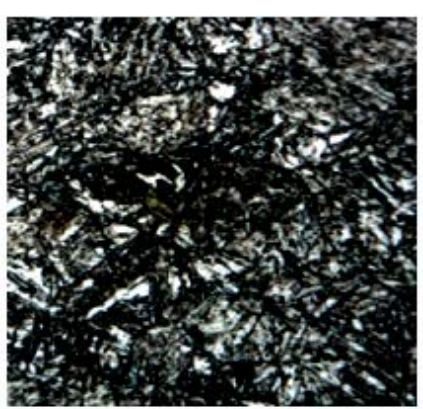

(a)

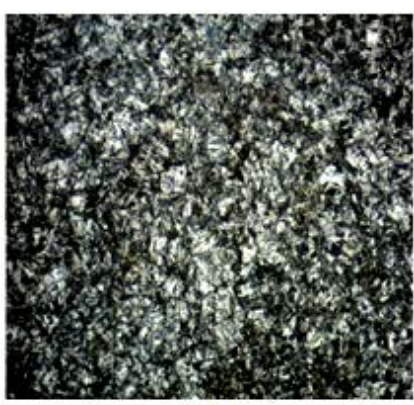

(b)

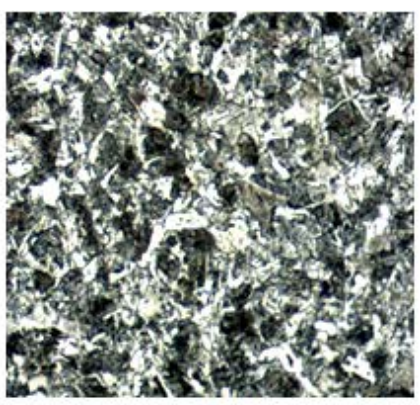

(c)

Figure 7. Optical micrographs showing the microstructures of (a) case, (b) transition and (c) core areas of steel 2 
From Figure 6 and Figure 7, it is revealed that case areas of both steels are composed of tempered martensitic structures. However, in transition and core areas, the microstructures are significantly different. In transition areas, microstructure of steel 1 is composed of fine pearlite (black grains) and ferrite (white grains), which is composed of tempered martensite and fine ferrite in steel
2. Very significant difference is also observed for core microstructures. For a properly heat treated TMT steel bars, the core microstructures should be fully composed of well developed ferrite and pearlite grains [12] and this has been observed for steel 1, Figure 6c. On the other hand, the ferrite-pearlite grains in core of steel 2 are significantly deviated from the standard microstructures.

Table 3. Tensile properties of TMT steel bars used

\begin{tabular}{|c|c|c|c|}
\hline Steel ID & Yield Strength (MPa) & Ultimate Tensile Strength (MPa) & Elongation (\%) \\
\hline 1 & 543 & 639 & 15 \\
\hline 2 & 594 & 723 & 11 \\
\hline
\end{tabular}

This type of deviation from standard microstructures means that there is residual stress in it. This residual stress is responsible for higher hardness values in the steel bars. From Table 2, it is clear that the case and core hardness of steel 2 is significantly higher than that of steel 1 . For hardened steels of similar chemical compositions or microstructures, higher residual stress induces more hardness along with high strength, which is also clear from Table 3.

From Table 3, it is very clear that the tensile strength (both yield and ultimate) strength of steel 2 is much higher than that of steel 1, which is also expected from its hardness values. Because of slight higher CE value, steel 2 might possess somewhat higher level of strength; however, the observed value is not compatible with its chemical compositions and standard heat treatment schedule to be followed for the production of TMT steel bars.
Considering the carbon equivalent, the resulted strength of steel 2 is arguable due to non-standard heat treatment practice during quenching of the hot rolled steel bars. It has already been mentioned that heat treatment schedule for TMT steel bar production is not very difficult. However, one should control the cooling rate of the surface area of the bar. As a standard practice, the surface temperature should be cooled to below $200^{\circ} \mathrm{C}$ within few seconds, whereas, the core temperature will remain nearly $800^{\circ} \mathrm{C}$ after leaving the water cooling chamber, Figure 8 $[17,18]$. If the above mentioned temperatures of different zones are achieved in the cooling chamber then, after about ten seconds, both the surface and core temperatures will be equalized to about $650^{\circ} \mathrm{C}$ on the cooling bed immediately after placing the steel bars over it. On this cooling bed, the steel bars will be finally cooled to room temperature.

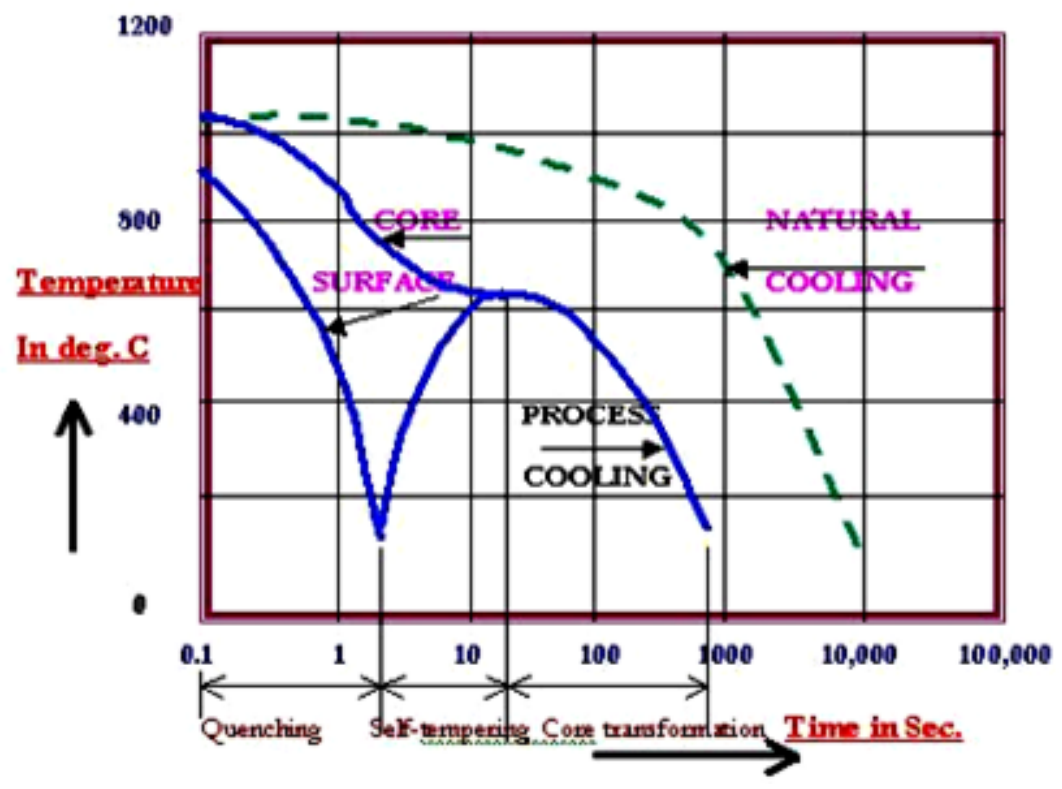

Figure 8. Diagram showing the standard heat treatment schedule for TMT steel bar production

Depending on chemical compositions of the hot rolled steel bars, cooling parameters might be adjusted for optimization of the mechanical properties of the steel bar. The possible problems in the heat treatment of steel 2 were; i. quenching rate was relative slow and ii. the hot rolled steel bar was in the water cooling chamber for a relatively longer period of time. As a result, the transition zone was highly affected. The larger area of transition zone of steel 2 presented in Figure 5 also suggests this. So, during final air cooling on the cooling bed, insufficient inner heat could not temper the martensitic case properly.
Improper tempering of the case means higher level of residual stress and higher strength/brittleness of the steel bar.

Here it is to be mentioned that the steel bars used in this research work were of locally produced $500 \mathrm{~W}$ grade. The number 500 means the yield strength of the steel bars is $500 \mathrm{MPa}$. As a result, the structural design stress is considered to be 500 for both steel bars. In this sense, additional strength is not useful for steel 2. Now the question, what will be possible future consequence for structures reinforced with this steel bar? This will be discussed below with fracture morphologies. 


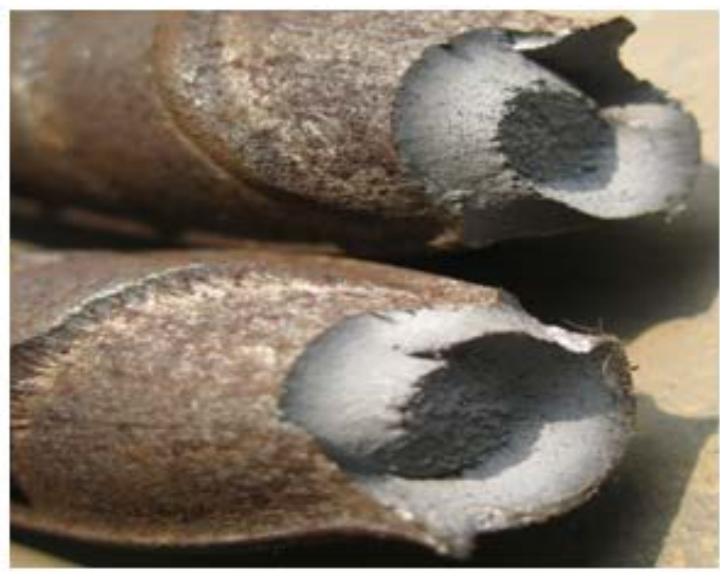

(a)

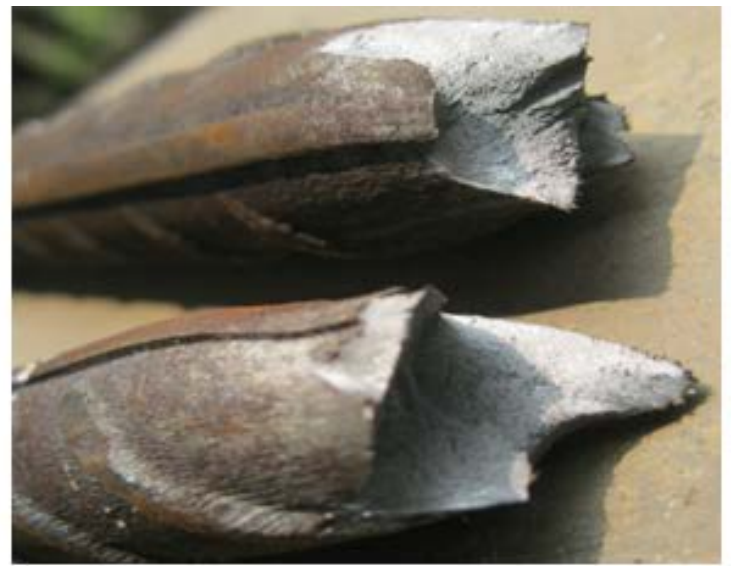

(b)

Figure 9. Optical macrographs showing the fracture modes of steels (a) 1 and (b) 2 with as-received ribs on the steel bars

Figure 9 presents the fracture modes of the steel bars used with as-received ribs on their surface. From this figure it is clear that steel 1 exhibited nearly cup and cone type fracture, which is the typical feature of any ductile fracture mode [19]. However, steel 2 exhibited brittle and shear type fracture mode. In the case of concrete reinforcing applications, ductile failure of the steel bar is very much expected. We know that concrete is a very brittle aggregate. Its compressive strength is very high;

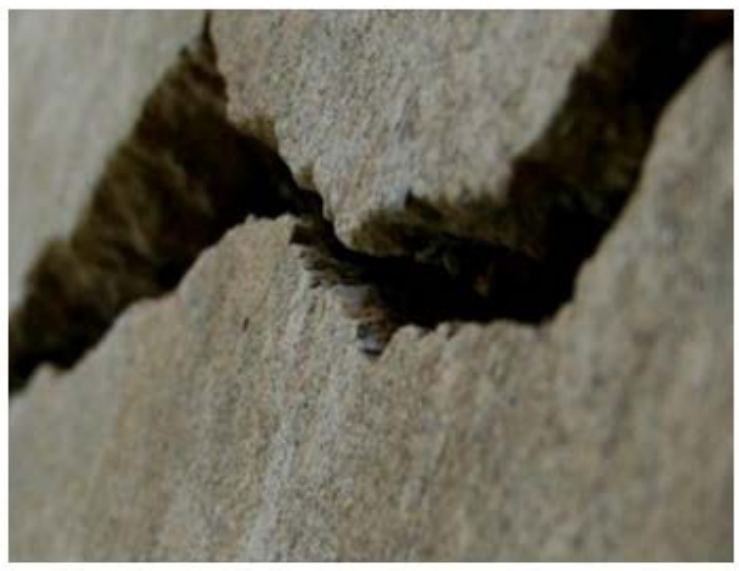

(a) however, the bending/tensile strength is very poor. If bending/tensile load is effective on any concrete block, it will crack easily and that the cracked portion will be fully separated from each other, Figure 10a. Reinforcing steel bars protects the concrete under tensile loading from easy cracking and also from collapse. Because of non-standard aggregates, casting or improper curing, concrete might be cracked, but reinforcing steel bars resist the sudden collapse of the concrete, Figure 10b.

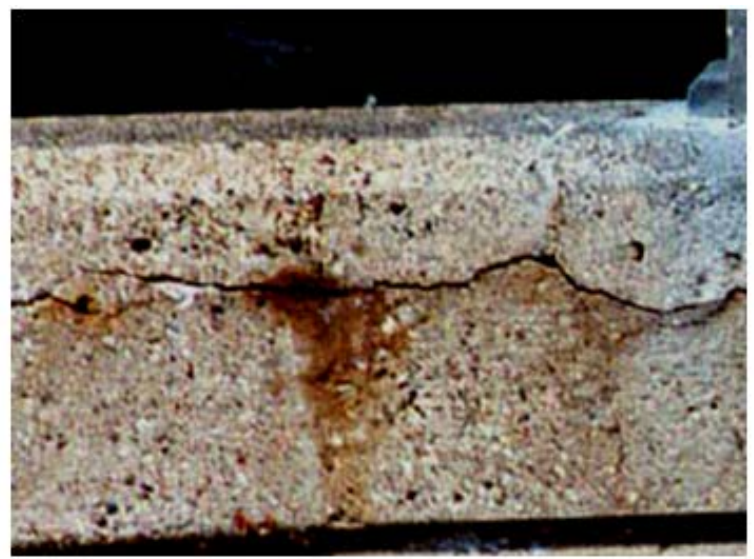

(b)

Figure 10. Optical macrographs showing the cracked concretes (a) without reinforcing steel bars and (b) with reinforcing steel bars

From above figures it is obvious that reinforcing steel bars play the necessary role to bear tensile loads over the concrete. Now, if the steel bars are very brittle then reinforced structures might experience catastrophic (sudden) failure with a huge loss both in lives and assets. The stress-elongation curves of steel 1 and 2 are shown in Figure 11. From this figure, one can observe that steel 1 exhibited clear yield point and more elongation with optimum yield strength level. For steel 2, the yield point is absent. This figure clearly indicates that steel 1 will provide better performance under service because of its good combination of tensile strength and ductility. However, reinforced structures with steel bars of type 2 might not be capable to perform its function properly. So, structure with this type of steel bars will be in danger, especially in the case of critical situation such as earthquake, cyclone on any other natural/manmade calamities. In this case, steel bars 2 will experience shear type of failure (Figure 8b), which is a typical fracture mode of brittle materials. As concrete itself is a brittle type material, then reinforcement of the concrete with brittle type steel bars will ultimately reduce the safety of the structures.

It has been mentioned that steel bar 2 retains more residual stress because of lack of tempering in the heat treatment schedule. It has been found that steel bars with higher residual stress will corrode at a higher rate [20,21]. In Bangladesh, both the atmospheric temperature and humidity are high. So, prevention of corrosion of steel bars is a real problem. Considering the practical environmental situation, heavy population and earthquake sensitivity of Bangladesh, construction industries must be aware of using steel bars of unnecessary strength of poor ductility. 


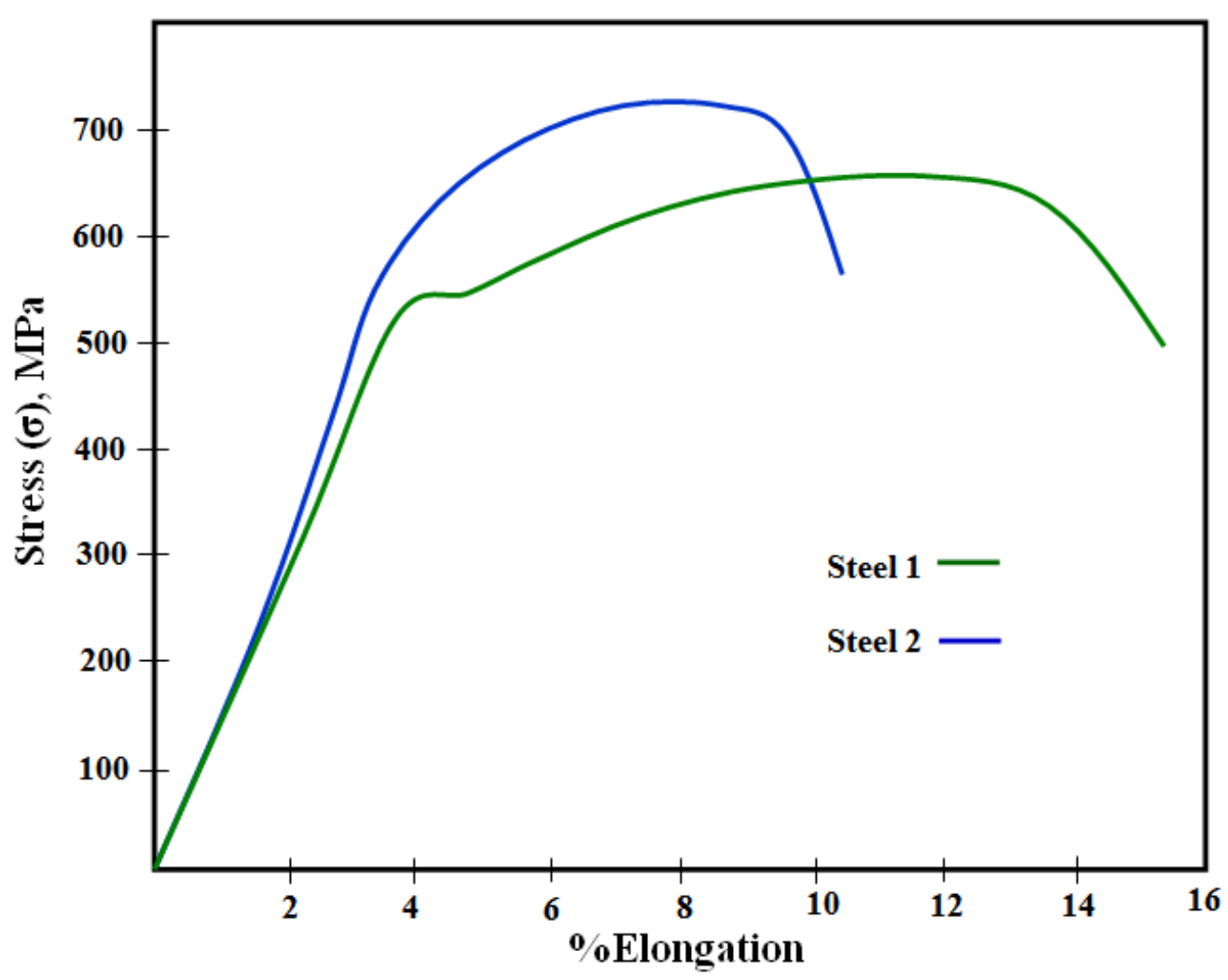

Figure 11. Stress-elongation curves of the reinforcing steel bars

For a very hard surface, notch sensitivity becomes severe. Surface roughness caused during the hot rolling and oxidation during heat treatment schedule on the steel bars might also act as a stress raiser [18]. Altogether, minor defects on the steel bars of excessive hardness/strength might cause shear type of failure. In order to observe the effect of unusual microstructures in the transition as well as in the core area, ribs and hardened case was machined out, Figure 4. After this type of machining, tensile tests of these steel bars were also conducted. The tensile fracture surfaces are presented in

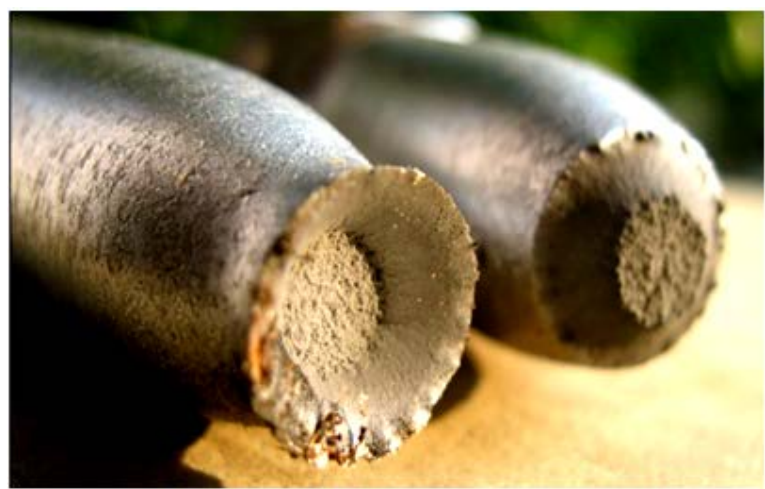

(a)
Figure 12. From Figure 12a, it is clear that steel 1 showed completely cup and cone type ductile fracture, whereas, for steel 2 the fracture mode is still shear dominating. This type fracture mode again reminds that the shear type of fracture mode in the steel bar 2 is not only for the rib associated surface roughness but also excessive hardness of the transition area and core. From this fractographic observation, it is quite clear that excessive transition area in the TMT steel bars might also cause brittle type catastrophic failure.

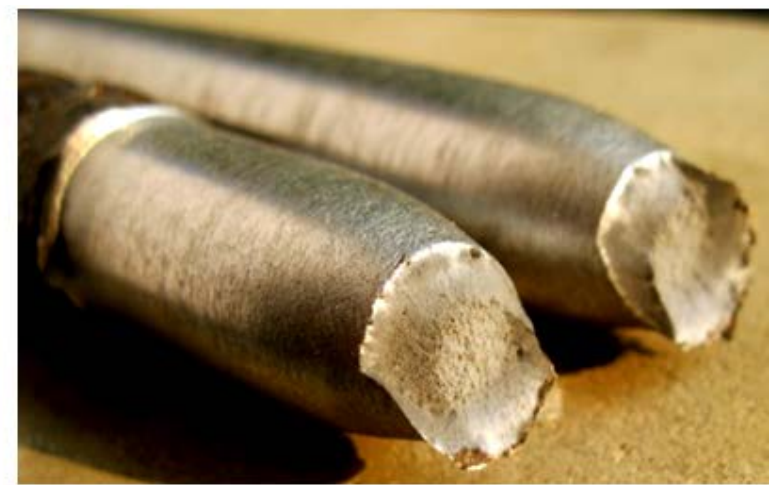

(b)

Figure 12. Optical macrographs showing the fracture modes of steels (a) 1 and (b) 2 after machining the as-received ribs and hardened case of the steel bars

\section{Conclusions}

In this steel bars, the effects of case and core hardness values and area fraction of transition zones on tensile behaviours of high strength TMT steel bars have been investigated. Special emphasis has been given on the possible fracture behaviours of the steel bars as well as the reinforced concrete, if excessively hard steel bars are used in practical applications. From this investigation, following conclusions are made.

1. Having similar level of hardened case depth, higher hardness of case areas induce unnecessarily high tensile strength with reduced ductility. 
2. Excessively high strength ultimately causes poor ductility in the reinforcing steel bars, which is responsible for unwanted shear type brittle fracture in the reinforcing steel bars.

3. Similar to very hard case, larger transition zone might also increase the chance of shear type brittle failure in the structures.

4. Experimental results revealed that, for optimization of the tensile properties as well as the unwanted shear type fracture behaviours of the TMT steel bars, the heat treatment parameters should be closely adjusted as per the chemical compositions of the hot rolled bars.

\section{References}

[1] D.L. Doushanov, "Control of Pollution in the Iron and Steel Industry”, Encyclopedia of Life Support Systems (EOLSS), vol.VIII, p.1-5.

[2] Report on "Available and Emerging Technologies for Reducing Greenhouse Gas Emissions from the Iron and Steel Industry” by Office of Air and Radiation, United States Environmental Agency, September 2012.

[3] Kopczynski, C., "High Strength Rebar Expanding Options in Concrete Towers”, Structure Magazine, vol.31, p.1-2, 2008.

[4] Jha, G., Singh, A.K., Bandyopadhyay, N. and Mohanty, O.N., "Seismic Resistant Reinforcing Bars", Journal of Practical Failure Analysis, ASM International, vol.5, p.53-56, 2001.

[5] Fazal, S., Kwok, J. and Salah, O., “Application of High-Strength and Corrosion-Resistant ASTM A1035 Steel Reinforcing Bar in Concrete of High-Rise Construction”, The Council on Tall Buildings \& Urban Habitat's, 8th World Congress, Dubai, p.1-6, 2008.

[6] Bari, M.S., "Use of 500 Grade Steel in the Design of Reinforced Concrete Slab”, BSRM Seminar, p.1-19, 2008.

[7] Noor, M.A. and Ahmed, A.U., "Study on Grade 75 and 60 Reinforcement in RC Design”, BSRM Seminar, p.1-12, 2008.

[8] Takashi, M., Kawano, O., Hayashida, T., Okamoto, R. and Taniguchi, H. "High Strength Hot-rolled Steel Sheet for
Automobiles”, Nippon Steel Technical Report No. 88, p.1-12, 2003.

[9] Beynon, D., Jones, T.B. and Fourlaris, G., "Effect of High Strain Rate Deformation on Microstructure of Trip Steels Tested Under Dynamic Tensile Conditions”, Materials Science and Technology, vol.21, no.1, p.103-112, 2005.

[10] Tomota, Y., Tokuda, H, Adachi, Y., Wakita, M., Minakawa, N., Moriai, A. and Morii, Y., "Tensile Behavior of TRIP-aided Multiphase Steel Studied by In-situ Neutron Diffraction”, Acta Materialia, vol.52, p.5737-5745, 2004.

[11] Hulka, K., "The Role of Niobium in Cold Rolled TRIP steel”, $J$. Materials Science Forum, vol.473, p.91-102, 2005.

[12] Panigrahi, B.K., Srikanth, S. and Sahoo, G., "Effect of Alloying Elements on Tensile Properties, Microstructure and Corrosion Resistance of Reinforcing Bar Steel”, J. Mat. Engg. Perform. ASM International, vol.18, p.1102-1108, 2009.

[13] Manoharan, R., Jayabalan, P. and Palanisamy, K., "Experimental Study on Corrosion Resistance of TMT Bar in Concrete”, ICCBT, p.239-250, 2008.

[14] R. Datta, R Veeraraghavan and K.L. Rohira, "Weldability Characteristics of Torr and Corrosion-Resistant TMT Bars Using SMAW Process”, Journal of Materials Engineering and Performance, ASM International, vol.11, p.369-375, 2002.

[15] P.C. Basu, P. Shylamoni and A.D. Roshan, "Characterization of steel Reinforcement for RC Structures: An Overview and Related Issue”, The Indian Concrete Journal, p.19-30, 2004.

[16] B.K. Panigrahi, "Microstructure-Related Properties of Some Novel Reinforced Bar Steel”, Journal of Materials Engineering and Performance, ASM International, vol.19, p.287-293, 2010.

[17] TMT bars manufacturing process: http://www.concretebasics.org/articlesinfo/tmt5.php.

[18] B.K. Panigrahi and S.K. Jain, "Impact toughness of High Strength Low Alloy TMT Reinforcement Ribbed Bar”, Bulletin of Materials Science, vol.25, no.4, p.319-324, 2002.

[19] M.A. Islam, "Low Temperature Fracture Toughness of Embrittled 2.25Cr-1Mo Pressure Vessel”, Ph.D Thesis, The University Of Birmingham, UK, 2001.

[20] J.L. Evins, "Dependence of Strength on Corrosion-fatigue Resistance of AISI4130 Steel” Master Thesis, Georgia Institute of Technology, April 2004.

[21] O. Kelestemur, M. Aksoy and S. Yildiz, "Corrosion behavior of tempered dual-phase steel embedded in concrete”, International Journal of Minerals, Metallurgy and Materials, vol.16, no.1, p.4350, 2009. 